\title{
A Comparative Assessment of Intraoperative Complication Rates in Resident-Performed Phacoemulsification Surgeries According to Najjar-Awwad Preoperative Risk Stratification
}

\author{
This article was published in the following Dove Press journal: \\ Clinical Ophthalmology
}

\section{Hamid Gharaee \\ Masoud Jahani (D) \\ Saeed Banan}

Eye Research Center, Mashhad University of Medical Sciences, Mashhad, Iran
Correspondence: Masoud Jahani $\mathrm{Tel}+9891 \mathrm{II} 760280$

Email Jahani.Masoud@yahoo.com
Introduction: Phacoemulsification cataract surgery presents a challenge to resident surgeons with lower experience, which confronts with patient safety. In this study, we compared major intraoperative surgical complications of resident-performed phacoemulsification surgeries between cases with low intraoperative risk and random cases with unknown intraoperative risk.

Methods: This prospective randomized controlled study was done on patients who underwent phacoemulsification surgery by third- and fourth-year residents in Khatam-al-Anbia eye hospital, Mashhad, Iran. Preoperative risk was calculated using Najjar-Awwad risk score after slit lamp examination and the patients with scores 7 or higher were considered highrisk. Patients were randomly assigned into a study group, in which only low-risk cases were operated by third-year residents, or control group, in which third-year residents were able to operate any patient regardless of the risk score. In both groups, the remaining patients were operated by fourth-year residents. All intraoperative complications were recorded. Data were analyzed using SPSS, considering $\mathrm{P}<0.05$ significant.

Results: Overall, 475 patients with cataract in the study $(\mathrm{N}=232)$ and control $(\mathrm{N}=243)$ groups were operated. Mean overall Najjar-Awwad risk scores did not differ significantly between the groups, but pseudoexfoliation and poor pupil dilatation occurred significantly more frequently in the control group $(\mathrm{P}=0.010$ and $\mathrm{P}=0.014$, respectively). Overall, 36 surgeries in the study group $(15.5 \%)$ and 47 surgeries in the control group (19.3\%) were complicated $(\mathrm{P}=0.273)$. There was a significant difference between the third- and fourth-year residents regarding the inability to complete continuous curvilinear capsulorhexis $(\mathrm{P}=0.033)$. The risk of overall and major complications in high-risk cases was significantly higher among those operated by 3rd-year residents compared with those operated by 4 th-year residents $(\mathrm{OR}=3.45,95 \% \mathrm{CI}=1.2-9.9, \mathrm{P}=0.016$ and $\mathrm{OR}=6.37,95 \% \mathrm{CI}=1.99-20.34, \mathrm{P}=0.001$, respectively).

Conclusion: Although supervised resident-performed phacoemulsification has a relatively safe learning curve in our residency program, it is best to stratify preoperative risk and assign high-risk cases to senior residents with higher experience.

Keywords: phacoemulsification, preoperative risk, intraoperative complications, resident

\section{Introduction}

One of the most common causes of age-related visual loss is cataract, whose prevalence is on the rise with the growing trend of aging in the general population, both in the developed and developing countries. This underscores the increasing 
need for more trained and experienced ophthalmologist surgeons in the near future. ${ }^{1-3}$

Recent advances in technology have led to drastic changes in surgical techniques used to perform cataract surgery. One of the crucial requisites during the ophthalmology residency program is phacoemulsification surgery, the main technique that is currently being taught to the majority of residents. Studies have shown that to achieve competency and obtain surgical skills in this regard, resident surgeons must perform a minimum of 70 operations. $^{4-7}$

Phacoemulsification cataract surgery constitutes over one third of all operations carried out by ophthalmology residents throughout the United States and there has been a growing trend in the number of phacoemulsification surgeries performed by residents in the past decade. $^{8,9}$

Risk factors such as old patient age, zonular weakness, poor red reflex, dense nuclear sclerosis, longer operation time of phacoemulsification, and history of vitrectomies have been reported for the occurrence of surgical complications in resident-performed cataract surgeries. Several studies have reported the surgical risks of residentperformed cataract surgeries and the attending surgeons might be reluctant to involve training residents in surgeries of challenging cases. However, it is vital for ophthalmology residents to perform surgery on challenging cases under expert supervision, to gain proper experience and necessary skills. Therefore, it is paramount to strike a balance between training programs of resident surgeons and patient safety in operative procedures such as phacoemulsification. ${ }^{10-16}$

In the present study, we compared major intraoperative surgical complications of resident-performed phacoemulsification surgeries between cases with low intraoperative risk and random cases with unknown intraoperative risk. The length of ophthalmology residency in Iran is 4 years and residents are allowed to perform phacoemulsification surgery under supervision in their third and fourth years. A third-year resident usually performs about 50 phacoemulsification surgeries while a fourth-year resident performs around 150, adding up to a total of 200 surgeries during the residency. ${ }^{17}$ We secondarily aimed to assess the intraoperative complications between third- and fourth-year residents to determine whether a higher experience is associated with a reduction in the rate of complications.

\section{Methods}

\section{Patients and Settings}

In this prospective randomized controlled study, all patients who referred to the anterior segment clinics of Khatam-al-Anbia Eye Hospital, Mashhad, Iran and underwent phacoemulsification cataract surgery by ophthalmology residents under expert supervision during SeptemberDecember 2014 were assessed. The study was approved by the Ethics Committee of Mashhad University of Medical Sciences. All enrolled patients signed informed written consent before they enter the study.

Patients with any of the following criteria were excluded from the study: posterior polar type of cataract, traumatic cataract, congenital cataract, and history of previous intraocular surgery including trabeculectomy or vitrectomy.

Keeping an alpha error of 0.05 and a beta of 0.2 , with $80 \%$ study power, the sample size was calculated to be 223 patients in each group, according to a previous study. ${ }^{18}$ However, considering about $10 \%$ of dropouts, we extended the sample size to 250 in each group.

\section{Surgical Procedures}

All cases underwent elective phacoemulsification surgery by third- or fourth-year ophthalmology residents under expert supervision with the relatively same technique. All operations were carried out under general or topical anesthesia (using tetracaine eye drop) in supratemporal or temporal positions, using two incisions in the superior and inferior parts of the cornea. Since the surgeries were performed in an educational center by resident surgeons, general anesthesia was the preferred method in most of the patients.

Diluted adrenaline was used in the anterior chamber to dilate the pupil. In some cases, the anterior capsule was stained using trypan blue dye. Low molecular weight $2 \%$ hydroxypropyl methylcellulose solution (Occu-Coat ${ }^{\circledR}$, Storz, Germany) was used in all surgeries. Then, continuous curvilinear capsulorhexis (CCC) was carried out. After performing hydrodissection and hydrodelineation, phacoemulsification was performed with PentaSys 2 Phacoemulsification Unit (Fritz Ruck, Germany), using either horizontal chop or stop-and-chop techniques.

In the next step, the cortical materials were removed through irrigation and aspiration and a foldable acrylic intraocular lens (IOL) was inserted into the capsular bag for uncomplicated patients or into the sulcus for complicated cases. After irrigation of the anterior chamber and 
remaining gels, all incisions were closed using hydration or 0-10 nylon sutures and the patients' eyes were sealed.

\section{Data Collection}

All eligible patients underwent a thorough slit lamp examination and a checklist indicating the pre-operative risk factors were completed for each patient by fourth-year residents. Then, the risk of cataract surgery for each case was determined using the Najjar-Awwad risk score. Patients with risk scores below 7 were considered as lowrisk and those with risk scores of 7 or above were considered high-risk.

Developed by Najjar and Awwad in 2003, the NajjarAwwad risk score has 12 items, of which three are basic items and 9 are additional points, totally composing an overall score of 25 (Table 1). Higher scores indicate higher surgical risk and higher complexity of phacoemulsification for resident surgeons. ${ }^{19}$ The score has been validated by Blomquist and colleagues in $2010 .^{20}$

For high hyperopia/myopia item, cases with anteroposterior globe diameter greater than $27 \mathrm{~mm}$ or lower than $21 \mathrm{~mm}$ were considered positive. For accurate determination of cataract density, the Lens Opacity Classification system (LOCS III) was used to classify the density of cataract. ${ }^{21}$

The patients were randomly divided into two groups. In the study group, the third-year residents were allowed to perform phacoemulsification cataract surgery only on lowrisk cases. In the control group, the third-year residents were able to perform phacoemulsification surgery on all cases, regardless of their cataract surgery risk score.

Any changes in the standard surgical procedures and techniques in case of any complications were done with the permission and supervision of an expert ophthalmologist. For instance, the inability to complete $\mathrm{CCC}$ and

Table I Comparison of Najjar-Awwad Risk Scores between the Study and Control Groups

\begin{tabular}{|c|c|c|c|}
\hline Parameter & Study $(\mathrm{N}=232)$ & Control $(\mathrm{N}=243)$ & $\mathbf{P}$ \\
\hline $\begin{array}{l}\text { Age, years } \\
\quad<50 \\
50-65 \\
66-80 \\
>80\end{array}$ & $\begin{array}{l}28(12.1 \%) \\
90(38.3 \%) \\
82(35.3 \%) \\
32(13.8 \%)\end{array}$ & $\begin{array}{l}27(11.1 \%) \\
102(42.0 \%) \\
92(37.2 \%) \\
22(9.1 \%)\end{array}$ & $0.403 *$ \\
\hline $\begin{array}{l}\text { Type of Anesthesia } \\
\text { General } \\
\text { Topical }\end{array}$ & $\begin{array}{l}211(90.9 \%) \\
21 \text { (9.1\%) }\end{array}$ & $\begin{array}{l}232(95.5 \%) \\
\mathrm{II}(4.5 \%)\end{array}$ & $0.057^{*}$ \\
\hline $\begin{array}{l}\text { Cataract Density } \\
\text { Moderate NS, mild-moderate ASC/PSC } \\
\text { Mild NS, mild-moderate ASC/PSC } \\
\text { Moderate NS, dense ASC/PSC } \\
\text { Mild NS, dense ASC/PSC } \\
\text { Dense NS, dense ASC/PSC }\end{array}$ & $\begin{array}{l}56(24.1 \%) \\
60(25.9 \%) \\
47(20.2 \%) \\
36(15.5 \%) \\
33(14.2 \%)\end{array}$ & $\begin{array}{l}57(23.5 \%) \\
64(26.4 \%) \\
54(22.2 \%) \\
42(17.3 \%) \\
26(10.7 \%)\end{array}$ & $0.664 *$ \\
\hline $\begin{array}{l}\text { Frontal bossing/sunken globes } \\
\text { High hyperopia/myopia (axial length<2 lor }>27 \mathrm{~mm} \text { ) } \\
\text { History of glaucoma, uveitis, or intraocular surgery } \\
\text { History of complications in the fellow eye } \\
\text { Shallow anterior chamber } \\
\text { Corneal cloudiness } \\
\text { Poor red reflex (possible use of capsule stain) } \\
\text { Pseudoexfoliation } \\
\text { Poor pupil dilatation } \\
\text { Overall risk score, mean ( } 95 \% \text { confidence interval) }\end{array}$ & $\begin{array}{l}26(11.2 \%) \\
21(9.1 \%) \\
12(5.2 \%) \\
5(2.2 \%) \\
21(9.1 \%) \\
23(9.9 \%) \\
45(19.4 \%) \\
13(5.6 \%) \\
17(7.3 \%) \\
6.12(5.79-6.45)\end{array}$ & $\begin{array}{l}31(12.8 \%) \\
24(9.9 \%) \\
18(7.4 \%) \\
4(1.6 \%) \\
26(7.1 \%) \\
17(7.0 \%) \\
43(17.7 \%) \\
30(12.3 \%) \\
35(14.4 \%) \\
6.26(5.91-6.61)\end{array}$ & $\begin{array}{l}0.604^{*} \\
0.760^{*} \\
0.321^{*} \\
0.754^{* *} \\
0.555^{*} \\
0.252^{*} \\
0.630^{*} \\
\mathbf{0 . 0 1 0 ^ { * }} \\
\mathbf{0 . 0 1 4 ^ { * }} \\
0.89 \mathbf{I}^{* * *}\end{array}$ \\
\hline $\begin{array}{c}\text { Risk Stratification } \\
\text { Low-risk }(<7) \\
\text { High-risk }(\geq 7)\end{array}$ & $\begin{array}{l}\text { I } 48 \text { (63.8\%) } \\
84(36.2 \%)\end{array}$ & $\begin{array}{l}160(65.8 \%) \\
83(34.2 \%)\end{array}$ & $0.640 *$ \\
\hline
\end{tabular}

Notes: *Chi-square test; **Fisher exact test; ***Mann-Whitney test; Bold figures show statistical significance $(\mathrm{P}<0.05)$.

Abbreviations: NS, nuclear sclerosis; ASC, anterior subcapsular opacities; PSC, posterior subcapsular opacities. 
conversion of the surgery to extracapsular cataract extraction (ECCE) or intracapsular cataract extraction (ICCE) were recorded in the checklists.

In both groups, all intraoperative complications were also entered into checklists and recorded after each surgery. These complications included anterior capsule tear, posterior capsule tear with vitreous prolapse or with intact anterior hyaloid face, zonular dehiscence with or without vitreous prolapse, nucleus drop, wound burn, Descemet's membrane detachment, and IOL drop.

\section{Statistical Analysis}

In this study, all statistical analyses were performed using SPSS software (version 20 for Windows; IBM Statistics, Chicago, IL). Frequency and percentage, mean, odds ratio (OR), and 95\% confidence interval (CI) were used to present the data. Kolmogorov-Smirnov test was used to investigate the data normality. Mann-Whitney $U$-test, Chisquare test, and Fisher exact test were used to compare data between different subgroups of patients. $\mathrm{P}<0.05$ was considered statistically significant in all tests.

\section{Results}

Initially, 500 patients were enrolled in the study, of which 25 (18 in the study group and 7 in the control group) were excluded the study because, in spite of the initial consent, they claimed unwillingness to be operated by residents, just before the surgery and the supervisor professor performed the surgery instead. Finally, 475 patients with cataract were studied in two groups of study ( $\mathrm{N}=232)$ and control $(\mathrm{N}=243)$. Males constituted 114 patients $(49.1 \%)$ of the study group and 125 patients $(51.4 \%)$ of the control group $(\mathrm{P}=0.620)$.

According to the Najjar-Awwad risk score, the frequency of different parameters of the pre-operative risk of patients in the study and control groups are compared in Table 1. As the table implies, mean overall Najjar-Awwad risk scores did not differ significantly between the two groups, but the frequency of two risk factors, namely pseudoexfoliation and poor pupil dilatation were significantly higher in the control group, compared with the study group $(\mathrm{P}=0.010$ and $\mathrm{P}=0.014$, respectively). Moreover, as shown in Table 1, there was no statistically significant difference regarding the frequency of high-risk patients (those with Najjar-Awwad risk score of 7 or more) between the study and the control group.

When comparing the frequency of surgeries performed by third-year versus fourth-year residents in each group, we found a significantly higher percentage of surgeries performed by third-year residents in the control group compared with the study group $(\mathrm{N}=73,30.1 \%$ vs $\mathrm{N}=47$, $20.3 \% ; \mathrm{P}=0.014$ ).

The frequency of intraoperative complications occurred in the study and control groups are compared between the third- and fourth-year residents in Table 2 . As the table shows, among all complications in the study group, only the frequency of inability to complete CCC was significantly different between the third- and fourthyear residents $(\mathrm{P}=0.008)$. However, the frequency of none of the complications differed significantly between the third- and fourth-year residents in the control group.

Besides, there was a significant difference between the third- and fourth-year residents regarding the inability to complete $\mathrm{CCC}(\mathrm{P}=0.033)$. However, no significant difference was found between the study and the control groups in terms of the frequency of complications.

Overall, apart from the need for suturing, 36 surgeries in the study group (15.5\%) and 47 surgeries in the control group $(19.3 \%)$ were complicated. There was no significant difference between the study and control group regarding the overall frequency of complications $(\mathrm{P}=0.273)$.

We also compared the risk of developing complications in both low-risk and high-risk cases between the operations performed by all third-year and fourth-year resident surgeons, regardless of the study or control groupings (Table 3). Regarding overall complications, the results showed a significantly higher risk for developing complications in cases operated by third-year residents, compared with those operated by fourth-year residents among the high-risk patients $(\mathrm{OR}=3.45,95 \% \mathrm{CI}=1.2-9.9, \mathrm{P}=0.016)$. On the other hand, the risk for developing complications among the low-risk patients was not significantly different between cases operated by third-year residents and those operated by fourth-year residents.

The risk of developing major complications (with vitreous prolapse) among the high-risk cases was 6.37 times higher in patients operated by third-year residents, compared with those operated by fourth-year residents $(95 \%$ $\mathrm{CI}=1.99-20.34, \mathrm{P}=0.001)$. However, among the low-risk cases, the risk for developing major complications was not significantly different between patients operated by thirdyear residents and those operated by fourth-year residents (Table 3).

The risk for developing minor complications (without vitreous prolapse) did not show any significant difference neither among the low-risk cases, nor among the high-risk ones, between patients operated by third-year residents and those operated by fourth-year residents (Table 3 ). 
Table 2 Intraoperative Complications Occurred in Patients

\begin{tabular}{|c|c|c|c|c|c|c|c|c|}
\hline \multirow[t]{2}{*}{ Complications } & \multicolumn{3}{|c|}{ Study $(\mathbf{N}=232)$} & \multicolumn{3}{|c|}{ Control $(\mathrm{N}=243)$} & \multirow[t]{2}{*}{$\mathbf{P I} *$} & \multirow[t]{2}{*}{ P2* } \\
\hline & $\begin{array}{l}\text { 3rd year } \\
(\mathrm{N}=47)\end{array}$ & $\begin{array}{l}\text { 4th year } \\
(\mathrm{N}=185)\end{array}$ & $\mathbf{P} *$ & $\begin{array}{l}\text { 3rd year } \\
(\mathrm{N}=73)\end{array}$ & $\begin{array}{l}\text { 4th year } \\
(N=170)\end{array}$ & $\mathbf{P} *$ & & \\
\hline Need for suturing & $4(8.5 \%)$ & $13(7.0 \%)$ & 0.820 & $10(13.7 \%)$ & $15(8.8 \%)$ & 0.191 & 0.424 & 0.210 \\
\hline Anterior capsule tear & $4(8.5 \%)$ & $9(4.8 \%)$ & 0.260 & $5(6.8 \%)$ & $9(5.3 \%)$ & 0.774 & 0.640 & 0.320 \\
\hline Inability to complete CCC & $3(6.3 \%)$ & $0(0.0 \%)$ & 0.008 & $4(5.8 \%)$ & $2(1.1 \%)$ & 0.202 & 0.344 & 0.033 \\
\hline $\begin{array}{l}\text { Posterior capsule tear with vitreous } \\
\text { prolapse }\end{array}$ & $4(8.5 \%)$ & $10(5.4 \%)$ & 0.492 & $9(12.3 \%)$ & $9(5.3 \%)$ & 0.720 & 0.811 & 0.055 \\
\hline $\begin{array}{l}\text { Posterior capsule tear with intact } \\
\text { anterior hyaloid face }\end{array}$ & $0(0.0 \%)$ & I (0.5\%) & $>0.999$ & $0(0.0 \%)$ & I $(0.5 \%)$ & $>0.999$ & $>0.999$ & $>0.999$ \\
\hline Zonular dehiscence with vitreous prolapse & $0(0.0 \%)$ & $0(0.0 \%)$ & - & $0(0.0 \%)$ & $0(0.0 \%)$ & 0.302 & $>0.999$ & 0.250 \\
\hline $\begin{array}{l}\text { Zonular dehiscence without vitreous } \\
\text { prolapse }\end{array}$ & $0(0.0 \%)$ & I (0.5\%) & $>0.999$ & $\mathrm{I}(\mathrm{I} .3 \%)$ & I (0.5\%) & 0.511 & $>0.999$ & $>0.999$ \\
\hline Nucleus drop & $0(0.0 \%)$ & $0(0.0 \%)$ & - & $\mathrm{I}(\mathrm{l} .3 \%)$ & $0(0.0 \%)$ & 0.307 & $>0.999$ & 0.251 \\
\hline Wound burn & $0(0.0 \%)$ & $0(0.0 \%)$ & - & $\mathrm{I}(\mathrm{l} .3 \%)$ & I (0.5\%) & 0.300 & $>0.999$ & 0.253 \\
\hline Descemet detachment & I (2.I\%) & $8(4.3 \%)$ & 0.732 & $\mathrm{I}(\mathrm{I} .3 \%)$ & $10(5.8 \%)$ & 0.122 & 0.730 & 0.123 \\
\hline Conversion to ECCE & $0(0.0 \%)$ & I (0.5\%) & $>0.999$ & $\mathrm{I}(\mathrm{I} .3 \%)$ & $\mathrm{I}(0.5 \%)$ & $>0.999$ & 0.902 & $>0.999$ \\
\hline Conversion to ICCE & $0(0.0 \%)$ & $0(0.0 \%)$ & - & $0(0.0 \%)$ & $0(0.0 \%)$ & - & - & - \\
\hline IOL drop & $0(0.0 \%)$ & $0(0.0 \%)$ & - & $0(0.0 \%)$ & $0(0.0 \%)$ & - & - & - \\
\hline
\end{tabular}

Notes: PI, P value of the comparison between study and control groups; P2, P value of the comparison between third and fourthyear residents; *Fisher exact test; Bold figures show statistical significance $(P<0.05)$.

Abbreviations: CCC, continuous curvilinear capsulorhexis; ECCE, extracapsular cataract extraction; ICCE, intracapsular cataract extraction; IOL, intraocular lens.

Table 3 Comparison of the Risk for Developing Complications in Low-Risk and High-Risk Cases between all Third-year and Fourth-year Residents

\begin{tabular}{|c|c|c|c|}
\hline Parameter & Risk & $\begin{array}{l}\text { Odds Ratio } \\
\text { (95\% CI) }\end{array}$ & P* \\
\hline Overall & High-risk ( $\geq 7)$ & 3.45 (1.2-9.9) & 0.016 \\
\hline complications & Low-risk (<7) & $2.64(1.27-5.48)$ & 0.090 \\
\hline Major complications & High-risk ( $\geq 7$ ) & 6.37 (1.99-20.34) & 0.001 \\
\hline $\begin{array}{l}\text { (with vitreous } \\
\text { prolapse) }\end{array}$ & Low-risk (<7) & $2.75(0.93-8.15)$ & 0.058 \\
\hline Minor complications & High-risk ( $\geq 7)$ & $0.93(0.25-3.48)$ & $>0.999$ \\
\hline $\begin{array}{l}\text { (without vitreous } \\
\text { prolapse) }\end{array}$ & Low-risk (<7) & $2.82(1.15-6.94)$ & 0.190 \\
\hline
\end{tabular}

Notes: ${ }^{*}$ Chi-square test; Bold figures show statistical significance $(\mathrm{P}<0.05)$.

\section{Discussion}

It is of cardinal importance for any resident in any field of medicine, especially those involving surgical and manual procedures like ophthalmology, to gain experience and obtain skills by independent practice under expert supervision. In this way, they can master skills and procedures, of which one salient example is phacoemulsification surgery. Several previous studies have indicated higher rates of intraoperative complications in less-experienced surgeons while performing phacoemulsification surgery. ${ }^{22-24}$
Likewise, several studies have reported a decline in the frequency of intraoperative complications as the eye surgeons who perform phacoemulsification gain more experience and carry out a sufficient number of surgeries. Different reports have indicated varying numbers between 40 and 80 surgeries for a junior resident surgeon to complete the learning curve of the phacoemulsification surgery and learn the necessary procedural skills. ${ }^{7,25-27}$

Although intraoperative complications undermine the chances for good visual outcomes in phacoemulsification surgeries, it is possible to achieve acceptable visual outcomes in complicated surgeries through proper management of the complications. However, it is best to avoid assigning complex and high-risk cataract surgeries to junior resident surgeons who still lack the required experience for performing phacoemulsification. This can optimize the outcomes of resident-performed surgeries. ${ }^{15,28,29}$

To this end, we carried out the present study to test the hypothesis indicating that stratification of the preoperative risk in phacoemulsification surgeries and assigning only the low-risk cases to less-experienced junior resident surgeons can decrease the risk of intraoperative complications. According to the Najjar-Awwad risk score, we calculated the preoperative risk score in each case, before they undergo surgery. However, unlike the initial 
recommendation of Najjar and Awwad for risk stratification (with score cut-off of 5), we used the risk score 7 as the cut-off point to discern low-risk cases from those with a high risk of complications. This was in line with the previous study by Blomquist and coworkers, who validated the Najjar-Awwad risk score for resident surgeons in the United States and recommended that cases with risk scores below 7 be given to the junior resident surgeons to avoid any serious intraoperative complication. ${ }^{20}$

The Najjar-Awwad risk score, which contains 12 items totally making an overall risk score of 25 , has been developed as an effective tool to evaluate the preoperative risk of patients undergoing phacoemulsification surgery, indicating the complexity of phacoemulsification for resident surgeons. ${ }^{19}$

To the best of our knowledge, this is the first study in Iran to calculate and stratify the preoperative risk in resident-performed phacoemulsification surgeries using Najjar-Awwad risk score and examine the effect of restricting the operations done by junior resident surgeons to low-risk cases. Moreover, although several studies have reported the preoperative risk of resident-performed surgeries and its association with intraoperative complications, our study is the first to investigate this issue in a prospective and controlled design, so far.

In this study, the study and control group had no significant differences in terms of sex, age, overall risk score, and frequency of high-risk cases, which helps to keep the confounding factors as fewer as possible. However, there was a significant difference regarding the percentage of surgeries performed by third-year residents between the study and the control group, which could have affected the results in some ways. However, this was predictable, as we considered no restrictions for performing surgeries by third-year residents in the control group.

Although we found no significant difference in mean overall Najjar-Awwad risk scores of the two groups, scores of pseudoexfoliation and poor pupil dilatation were significantly higher in the control group, compared with the study group.

Our results indicated that the overall rate of complications was $15.5 \%$ in the study group and $19.3 \%$ in the controls. We found no significant difference in the rate of intraoperative complications between the study and control groups. This is in stark contrast with the results of a study by Tsinopoulos et al, who found a significantly higher rate of intraoperative complications in phacoemulsification surgeries performed by residents with varying experience compared with those performed by residents after applying a risk stratification system $(7.2 \%$ vs $3 \%){ }^{12}$ This inconsistency can be attributed to the difference in risk stratification systems, as Tsinopoulos et al used the risk score developed by Muhtaseb, which categorizes the patients into three groups according to their preoperative risk for phacoemulsification, ${ }^{30}$ but we used the Najjar-Awwad risk score. The difference in results can also be ascribed to the differences in sample sizes and designs of the two studies.

Our results regarding the overall rate of complications were similar to the findings of Al-Jindan et al who reported the overall complication rate of $17.5 \%$ in resident-performed phacoemulsification surgeries. However, our overall complication rate was lower than the ones reported by Mangan et al (23.3\%), Lee et al (27.4\%), and Lomi et al $(37 \%)$, and higher than the rates reported by Blomquist et al (6.5\%), Randleman et al (5.0\%), Carricondo et al (11.5\%), Tsinopoulos et al (7.2\%), and Hashemi et al $(10.2 \%)$, all assessing resident-performed phacoemulsification surgeries. $7,10,12,16,20,26,31-33$

Our findings indicated a rate of $6.5 \%$ for major complications (those including posterior capsule rupture and vitreous prolapse). This rate comes very close to the rates reported by and Carricondo et al, Unal et al, Randleman et al, Tayanithi et al, Al-Jindan et al with $6.13 \%, 6.4 \%, 6.7 \%, 6.9 \%$, and $7 \%$ vitreous prolapse/loss complication rates in the resident-performed phacoemulsification surgeries, respectively. ${ }^{4,5,24,26,31}$ Other studies have also reported similar but slightly lower rates, ranging from $3.2 \%$ to $4.9 \%$, for vitreous prolapse/loss complications in resident-performed phacoemulsification surgeries. ${ }^{14,15,20,28,32,34}$ However, higher rates of major complications in resident-performed phacoemulsification surgeries were reported by Mangan et al (8.8\%), Hashemi et al (9.6\%), and Lomi et al (21\%). ${ }^{10,16,33}$

Several reasons can be stated for the inconsistencies between the overall and major complication rates in our study and the abovementioned studies, including different exclusion criteria, different residency-training programs, different instruments and units, as well as different surgical techniques used for phacoemulsification. It can also be attributed to the difference in rate of interventions by attending supervisor the surgeries performed by residents.

As the study by Hashemi et al was performed in Iran and the residency programs are fairly similar in our center and theirs, we can posit that our rate of overall complications in resident-performed phacoemulsification surgeries was relatively higher while our rate of major complications was lower, compared with those reported by 
Hashemi et al. ${ }^{16}$ This indicates a generally acceptable residency-training program in our center.

Findings of the present work showed a significantly higher risk (3.45 fold higher) for developing any complication in high-risk cases operated by third-year residents, compared with high-risk cases operated by fourth-year residents. The risk was even greater (6.37 times higher) for developing major complications (with vitreous prolapse) among the high-risk cases operated by third-year residents, compared with those operated by fourth-year residents. However, among the low-risk cases, the risk for developing complications was not significantly different between patients operated by third-year residents and fourth-year residents.

We found a significantly higher frequency of inability to complete CCC in the third-year residents compared with fourth-year residents, which was relatively expectable considering the difference in their experience. Moreover, the frequency of vitreous prolapse was also higher in third-year residents but was on the verge of statistical significance. The latter is, however, a key determinant in distinguishing a seriously complicated surgery from an uncomplicated or minimally complicated one and thus should not be taken lightly.

There was no significant difference between the thirdand fourth-year residents in the overall frequency of complications. In contrast to our study, senior residents had a higher rate of complications in comparison with lessexperienced residents as reported in studies by Mangan et al and Al-Jindan et al. ${ }^{26,33}$ This inconsistency might be due to the higher rate of supervisor interventions in surgeries done by the junior resident surgeons, compared to those performed by senior ones in the cited studies.

One limitation of our study was that different residents completed the Najjar-Awwad risk score and the complication checklist for the patients and their evaluation may differ from one to the other. We tried to make the evaluations as objective as possible through defining precise criteria for each risk factor in order to lower the chance of bias. However, we recommend that all patients be evaluated by one operator for future studies. Another limitation was that we did not record the time, extent, and method of interventions done by supervising attending professors. The interventions might have been inevitably varying between different supervisors, which could have affected the results. Finally, different proportions of surgeries performed by third-year residents between the study and the control groups could have resulted in bias. We recommend matching this item, as well as other confounding factors, in further studies. However, despite all the mentioned limitations, our findings can be extrapolated to other residency programs in Iran.

In conclusion, we can state that phacoemulsification has a relatively safe learning curve in our residency program and it can be performed by residents under supervision. However, it is best to conduct preoperative risk stratification to assign high-risk complex cases to senior residents with higher experience. This can be paramount in reducing complication rate and subsequently, treatment costs will decline.

\section{Disclosure}

The authors report no conflicts of interest in this work.

\section{References}

1. Chua J, Lim B, Fenwick EK, et al. Prevalence, risk factors, and impact of undiagnosed visually significant cataract: the Singapore epidemiology of eye diseases study. PLoS One. 2017;12:e0170804. doi:10.1371/journal.pone. 0170804

2. Park SJ, Lee JH, Kang SW, Hyon JY, Park KH. Cataract and cataract surgery: nationwide prevalence and clinical determinants. $J$ Korean Med Sci. 2016;31:963-971. doi:10.3346/jkms.2016.31.6.963

3. Beaver HA. Cataracts and cataract surgery. In: Beaver H., Lee A. (eds)Geriatric Ophthalmology. Springer; 2019:15-26.

4. Ünal M, Yücel İ, Sarıcı A, et al. Phacoemulsification with topical anesthesia: resident experience. J Cataract Refract Surg. 2006;32: 1361-1365. doi:10.1016/j.jcrs.2006.02.063

5. Randleman JB, Srivastava SK, Aaron MM. Phacoemulsification with topical anesthesia performed by resident surgeons. $J$ Cataract Refract Surg. 2004;30:149-154. doi:10.1016/S0886-3350(03)00491-7

6. Kaplowitz K, Yazdanie M, Abazari A. A review of teaching methods and outcomes of resident phacoemulsification. Surv Ophthalmol. 2018;63:257-267. doi:10.1016/j.survophthal.2017.09.006

7. Randleman JB, Wolfe JD, Woodward M, Lynn MJ, Cherwek DH, Srivastava SK. The resident surgeon phacoemulsification learning curve. Arch Ophthalmol. 2007;125:1215-1219. doi:10.1001/archopht. 125.9.1215

8. Klein BE, Howard KP, Lee KE, Klein R. Changing incidence of lens extraction over 20 years: the Beaver Dam eye study. Ophthalmology. 2014;121:5-9. doi:10.1016/j.ophtha.2013.06.006

9. ACGME. Accreditation Council for Graduate Medical Education (ACGME). Ophthalmology case logs: National data report, 2010-2019. Available from: https://www.acgme.org/Data-CollectionSystems/Case-Log-Graduate-Statistics. Accessed February 4, 2020.

10. Lomi N, Sharma R, Khokhar S, Dada T, Vanathi M, Agarwal T. Risk factors for intra-operative complications during phacoemulsification performed by residents. Int Ophthalmol. 2016;36:401-406. doi:10.10 07/s10792-015-0146-7

11. Menda SA, Driver TH, Neiman AE, Blumberg S, Naseri A, Stewart JM. Risk factors for return to the operating room after resident-performed cataract surgery. Seminars in Ophthalmology. 2018;33:210-214. doi:10.1080/08820538.2016.1208760

12. Tsinopoulos IT, Lamprogiannis LP, Tsaousis KT, et al. Surgical outcomes in phacoemulsification after application of a risk stratification system. Clin Ophthalmol. 2013;7:895. doi:10.2147/OPTH.S42726

13. Rutar T, Porco TC, Naseri A. Risk factors for intraoperative complications in resident-performed phacoemulsification surgery. Ophthalmology. 2009;116:431-436. doi:10.1016/j.ophtha.2008.10.028 
14. Blomquist PH, Morales ME, Tong L, Ahn C. Risk factors for vitreous complications in resident-performed phacoemulsification surgery. J Cataract Refract Surg. 2012;38:208-214. doi:10.1016/j.jcrs.2011. 10.001

15. Briszi A, Prahs P, Hillenkamp J, Helbig H, Herrmann W. Complication rate and risk factors for intraoperative complications in resident-performed phacoemulsification surgery. Graefes Arch Clin Exp Ophthalmol. 2012;250:1315-1320. doi:10.1007/s00417-012-2003-y

16. Hashemi H, Mohammadpour M, Jabbarvand M, Nezamdoost Z, Ghadimi $H$. Incidence of and risk factors for vitreous loss in resident-performed phacoemulsification surgery. $J$ Cataract Refract Surg. 2013;39:1377-1382. doi:10.1016/j.jcrs.2013.03.028

17. Hashemi H, Babamahmoodi A, Fotouhi A, Asgari S. Revisiting the cataract surgery curriculum for ophthalmology residents: a narrative review. Iran J Ophthalmol. 2014;26:178-182.

18. Bergqvist J, Person A, Vestergaard A, Grauslund J. Establishment of a validated training programme on the Eyesi cataract simulator. A prospective randomized study. Acta Ophthalmol. 2014;92: 629-634. doi:10.1111/aos. 12383

19. Najjar DM, Awwad ST. Cataract surgery risk score for residents and beginning surgeons. J Cataract Refract Surg. 2003;29:2036-2037. doi:10.1016/j.jcrs.2003.08.004

20. Blomquist PH, Sargent JW, Winslow HH. Validation of Najjar-Awwad cataract surgery risk score for resident phacoemulsification surgery. J Cataract Refract Surg. 2010;36:1753-1757. doi:10.1016/j.jcrs.2010.04.035

21. Chylack LT, Wolfe JK, Singer DM, et al. The lens opacities classification system III. Arch Ophthalmol. 1993;111:831-836. doi:10.1001/ archopht.1993.01090060119035

22. Johnston R, Taylor H, Smith R, Sparrow J. The Cataract National Dataset electronic multi-centre audit of 55567 operations: variation in posterior capsule rupture rates between surgeons. Eye. 2010;24:888-893. doi:10.1038/eye.2009.195

23. Artzén D, Lundström M, Behndig A, Stenevi U, Lydahl E, Montan P. Capsule complication during cataract surgery: case-control study of preoperative and intraoperative risk factors: Swedish Capsule Rupture Study Group report 2. J Cataract Refract Surg. 2009;35:1688-1693. doi:10.1016/j.jcrs.2009.05.026

24. Tayanithi P, Pungpapong K, Siramput P. Vitreous loss during phacoemulsification learning curve performed by third-year residents. J Med Assoc Thai. 2005;88:S89-S93.
25. Taravella MJ, Davidson R, Erlanger M, Guiton G, Gregory D. Characterizing the learning curve in phacoemulsification. J Cataract Refract Surg. 2011;37:1069-1075. doi:10.1016/j.jcrs.2010.12.054

26. Al-Jindan M, Almarshood A, Yassin SA, Alarfaj K, Al Mahmood A, Sulaimani NM. Assessment of Learning curve in phacoemulsification surgery among the Eastern province ophthalmology program residents. Clin Ophthalmol. 2020;14:113. doi:10.2147/OPTH.S241 250

27. Rogers GM, Oetting TA, Lee AG, et al. Impact of a structured surgical curriculum on ophthalmic resident cataract surgery complication rates. J Cataract Refract Surg. 2009;35:1956-1960. doi:10.10 16/j.jcrs.2009.05.046

28. Blomquist PH, Rugwani RM. Visual outcomes after vitreous loss during cataract surgery performed by residents. $J$ Cataract Refract Surg. 2002;28:847-852. doi:10.1016/S0886-3350(01)01117-8

29. Kim JY, Ali R, Cremers SL, Yun S-C, Henderson BA. Incidence of intraoperative complications in cataract surgery performed by left-handed residents. J Cataract Refract Surg. 2009;35:1019-1025. doi:10.1016/j.jcrs.2009.01.025

30. Muhtaseb M, Kalhoro A, Ionides A. A system for preoperative stratification of cataract patients according to risk of intraoperative complications: a prospective analysis of 1441 cases. $\mathrm{Br}$ J Ophthalmol. 2004;88:1242-1246. doi:10.1136/bjo.2004.046003

31. Carricondo PC, Fortes ACFM, Mourão P, Hajnal M, Jose NK. Senior resident phacoemulsification learning cure. Arq Bras Oftalmol. 2010;73:66-69. doi:10.1590/S0004-27492010000100012

32. Lee J, Hou C, Yang M, Kuo JZ, Lin K. A different approach to assess resident phacoemulsification learning curve: analysis of both completion and complication rates. Eye. 2009;23:683-687. doi:10.1038/sj. eye. 6703103

33. Mangan MS, Atalay E, Arıcı C, Tuncer İ, Bilgeç MD. Comparison of different types of complications in the phacoemulsification surgery learning curve according to number of operations performed. Turk J Ophthalmol. 2016;46:7. doi:10.4274/tjo.83788

34. Woodfield AS, Gower EW, Cassard SD, Ramanthan S. Intraoperative phacoemulsification complication rates of second-and third-year ophthalmology residents: a 5-year comparison. Ophthalmology. 2011;118:954-958. doi:10.1016/j.ophtha.2010.08.047
Clinical Ophthalmology

\section{Publish your work in this journal}

Clinical Ophthalmology is an international, peer-reviewed journal covering all subspecialties within ophthalmology. Key topics include: Optometry; Visual science; Pharmacology and drug therapy in eye diseases; Basic Sciences; Primary and Secondary eye care; Patient Safety and Quality of Care Improvements. This journal is indexed on PubMed
Central and CAS, and is the official journal of The Society of Clinical Ophthalmology (SCO). The manuscript management system is completely online and includes a very quick and fair peer-review system, which is all easy to use. Visit http://www.dovepress.com/ testimonials.php to read real quotes from published authors.

\section{Dovepress}

